\title{
Os anõezinhos fora do lugar ${ }^{1}$ \\ Marisa Lajolo
}

Para os parceiros Márcia e Vladimir

\section{Monteiro Lobato, cidadão da modemidade}

Enterrado no Cemitério da Consolação em São Paulo, aonde o conduziu imenso e comovido cortejo de muitos milhares de pessoas, Monteiro Lobato deixa marcas profundas na cultura brasileira. Sua herança se faz presente, por exemplo, no perfil moderno da indústria livreira que criou, e também na problematização de diversos aspectos de práticas brasileiras de escrita e de leitura, da produção e da circulação de livros. Lobato foi dos primeiros (e raros) intelectuais a perceber a profunda alteração pela qual passavam, na modernidade, livros e leituras.

Incompreensão e preconceito face à materialidade da escrita e da leitura têm história longa na tradição ocidental, que tanto desqualifica e apaga a dimensão econômica das atividades culturais, quanto postula a incompatibilidade entre a dimensão produtiva de tais atividades e sua dimensão propriamente intelectual. ${ }^{2}$ Já na enciclopédia, e na esteira do (segundo Darnton ${ }^{3}$ ) rendoso negócio do Iluminismo, Diderot e d' Alambert afirmavam a incompatibilidade entre letras e cifrões:

[...] nada se conjuga pior do que a vida ativa do comerciante e a vida sedentária do homem de letras. Incapazes que somos de uma infinidade de pequenas tarefas, em cem autores que pretenderem explorar por si próprios as suas obras, haverá 99 que se sairão mal e se enfastiarão de tal atividade. (р. 447)

Dessa opinião, seguramente, não compartilhava Monteiro Lobato que, conjugando uma sólida vida intelectual a um cotidiano atarefado de empresário, durante toda sua vida viveu de livros. Como escritor, como 
editor e como tradutor sustentou sua numerosa família e já em 1909 contava ao cunhado a perspectiva da qual encarava sua colaboração na imprensa:

[...] hoje só concebo que se extravase pelo bico da pena tantos ideais sobre umas tantas tiras de papel quando alguma vantagenzinha resulta disso [...] e se há alguma compensaçãozinha eu mandarei para A tribuna ver um conto já escrito Boca torta e um artigo que posso escrever já - A futura guerra anglo-alemã. ${ }^{4}$

Dez anos depois, e coerentemente com a posição de dono de editora que então era, Monteiro Lobato insiste na dimensão econômica do trabalho intelectual, fazendo blague com o amigo e correspondente de toda a vida, Godofredo Rangel:

[...] que sórdido fiquei! Como estou traindo o Ricardo! Olegário Ribeiro, Lobato \& Cia Ltda. - vê que horror! Meu nome, que aparecia no alto dos livros ou embaixo de artigos virou agora objeto de registro na Junta Comercial. ${ }^{5}$

Essa aguda consciência da dimensão econômica de livros e leitura é uma das maiores marcas da modernidade de Monteiro Lobato. Para além da correspondência, ela encontra farta sustentação dentro de sua obra.

Num interior de poucas letras e poucos livros, Dona Benta os encomendava a livreiros da capital para deleite da platéia para quem ela lia ou contava as histórias dos livros que the chegavam pelo correio. Ou seja, a ficção infantil lobatiana promove a mímese de modos de venda senão instaurados, pelo menos desejáveis para Lobato, numa espécie de contrapartida ficcional - e também pedagógica - das providências que, como editor, ele tomava para entupir de livros os rincões brasileiros. ${ }^{6}$

Ainda manifestação da modernidade lobatiana é sua consciência da segmentação do mercado de livros e da importância aí do segmento representado pela literatura infantil e pela escolar. Tem também o mes- 
mo sentido sua compreensão da complexidade da infra-estrutura necessária à circulação e ao consumo do livro brasileiro em escala financeiramente compensadora. Lobato compreende bem a necessidade de agilizar a distribuição do livro, o que, no caso dos títulos de sua editora, dá - se através de diferentes iniciativas.

Dá-se, por exemplo, pela utilização de pontos não convencionais de venda, como bazares e farmácias. Dá-se também pela aproximação do escritor-editor, quer do aparelho escolar, como foi o caso da venda maciça ao governo paulista de Narizinho arrebitado (lançado em 1921), quer da indústria, que funciona como parceira, como ocorreu quando o Jeca vendia Biotônico Fontoura e Ankilostomina, produtos do Laboratório Fontoura, então propriedade de um velho amigo de Lobato. ${ }^{7}$

Com tal currículo, não é de estranhar que Lobato invista na propaganda dos livros que editava (próprios e alheios) através de matérias em jornais e revistas, ${ }^{8}$ em textos não poucas vezes encomendados a amigos.

Coroa e traduz o esforço de Monteiro Lobato pela profissionalização do campo literário, o pragmatismo às vezes agressivo das metáforas com as quais, ao longo de toda a vida, ele fala de seus livros e de seus leitores, chamando uns de vaquinhas que lhe dão leite e outros de figuras às quais se deve enfiar o livro güela abaixo.

Cada livro considero uma vaca holandesa que me dá o leite da subsistência. O meu estábulo no Brasil conta com 23 cabeças no Octales, mais 12 na brasiliense e mais as 30 obras completas. Total: 65 vacas de 40 litros. E o meu estábulo na Argentina conta com 37 cabeças. Grande total, lá e cá: 102 cabeças. ${ }^{9}$

\section{O saci pererê numa ciranda de anõezinhos}

A modernidade lobatiana expressa-se de forma extremamente original no até hoje pouco conhecido O Sacy Pererê (resultado de um in- 
quérito). ${ }^{10}$ Livro de estréia de Monteiro Lobato, em seu interior encontramos uma manifestação bastante peculiar de sua precoce sintonia com práticas de propaganda, marketing e merchandising, surpreendentes ainda hoje.

A obra, fruto do que hoje se chamaria pesquisa de opinião, investiga representações populares do saci pererê, registrando depoimentos e causos. Da pesquisa, organizada e dirigida por Lobato, resultou o livro que foi impresso em 1918 na Seção de Obras do jornal O Estado de S. Paulo (da qual leva a chancela). Na introdução, Lobato atribui a idéia da pesquisa e do livro dela resultante à indignação que lhe provocou um nada tropical conjunto de anõezinhos de jardim que enfeitavam, a seu ver indevidamente, o Jardim da Luz de São Paulo.

Crendo com firmeza que se tratava de anõezinhos fora do lugar, ainda na introdução do livro, Lobato desfia uma deliciosa catilinária contra o europeismo dos valores culturais brasileiros, verberando a geral e profunda ignorância relativa às figuras do nosso imaginário, entre elas o saci. Neste terçar armas com a importação cultural, Lobato antecipa de dez anos o antropofágico repto oswaldiano "Tupi or not Tupi: that is the question".

É dessa indignação face aos anõezinhos do Jardim da Luz que nasce o projeto da pesquisa, anunciando que em 25 de janeiro de 1917

O Estadinho inaugura [...] uma série de estudos em que todos são chamados a colaborar. Abre um inquérito ou "enquete" como dizo Trianon na sua meia lingua. Sobre o futuro presidente da República? Não. Sobre o sacy. (p. 18)

O livro de 1918, como indica seu subtítulo, é o resultado dessa pesquisa que transcreve mais de setenta depoimentos recebidos em variada formatação. Tem de tudo: artigos em prosa e em verso, alguns com nome e sobrenome de quem faz o depoimento, outros anônimos ou com pseudônimo, alguns crédulos e outros descrentes, muitos tratando o assunto com empáfia e arrogância; uns em tom de sinceridade e outros 
temperados com tais e tantos traços de ironia que a idéia de pastiche é quase irresistível, como por exemplo o depoimento de Luigi Cappalunga cuja linguagem lembra muito o italiano macarrônico que Juó Bananere ${ }^{11}$ consagrara entre 1911 e 1915 nas páginas de O Pirralho.

\begin{abstract}
Ebbene. In quello tempo ch'io mi sono arrivato a questo paese, tutto stava moltos trazado. Il mio caro Buô Ritiro non era che un piccolo paesino senz̧a portanza; quello affare di "progrezzo" non'era ancora arrivato a Zampaolo; i bondis si dexávonno puxá co 'us burrinho e nisciuno si pensava dalla letricitá; la rua Quindice Novembre si chiamava "Peratrice". In quello tempo si! ce si garava la vita zocegáto... É veritade ch 'io fece qualche cosa; ma poteva fare di piú, - porca miseria, perché tuttas a gende erano "troxa". Oggi... stanno a Zampaolo certi gavatori d'un cane...
\end{abstract}

\footnotetext{
A milla ottocento zincuanta réte, quindi, - $i$ Zazi andavanno da'apertutto Zanpaolo e non s'importavanno co nisciuno.
}

Oggi, veramente $i$ Zaz̧i stanno ficano "arisco" pê motivo che us pretto stanno cabano. (Perché il vero Zaẓi, quello liggitimo, era uno prettinho grazatinho, molto birbante, molto figlio d'un cane). (pp. 259 - 260)

Antecede os depoimentos uma breve apresentação seus autores. Da lavra de Lobato, algumas destas apresentações em estilo irônico e bem - humorado - vão sugerindo ao leitor o ponto de vista do organizador do livro. A autoria lobatiana, forte e indisfarçável, manifesta-se, por exemplo, a propósito do depoimento do sr. Belmiro Aranha, de quem Lobato informa que

Vem de Pitangueira. Não está averiguado que lá haja pitangas, mas há sacis, o que é uma compensação. (p. 105) 
A propósito da autora de um depoimento que parodia uma redação escolar empolada, Lobato diz que ela

Chama-se M. Aurorita. Tem apenas 16 anos. E o seu depoimento exala masculinidade. Desconfio dela. É uma aurora a falar da meia noite com erudição de curiango. (p. 91)

Intercalam-se aos depoimentos reproduções de pinturas e estatuetas $^{12}$ representando a figura do Sacy, e do livro consta também a partitura de uma polca de Nogueira Lima. ${ }^{13}$

O resultado da pesquisa rende dividendos a Monteiro Lobato, que posteriormente aproveita o material tanto em sua obra infantil como na voltada para adultos. O saci aparece na fantástica aventura de Pedrinho às voltas com várias personagens da mitologia brasileira narrada na obra homônima (O Saci, 1921) e no conto Pedro Pichorra (incluído em Cidades Mortas, 1919). Lobato reaproveita, assim, elementos da pesquisa reunida no livro de 1918, sugerindo, ao lado do agudo senso prático do nativo de áries, a consistência com que o tema lança raízes em sua produção.

Mas essa obra de estréia é ainda por outras razões fundadora. Evoca em sua abertura uma antiga negra que trabalhava na casa da família de Lobato - Tia Esméria - a cuja memória o livro é dedicado, registrando-se nessa dedicatória uma eventual fonte de inspiração para a criação de Tia Nastácia, pivô da polêmica relativa à posição de Lobato face à questão racial no Brasil: ${ }^{14}$

À memória da saudosa Tia Esméria, e de quanta preta velha nos pôs, em criança, de cabelos arrepiados, com histórias de cucas, sacis e lobisomens, tão mais interessantes que as larachas contadas hoje aos nossos pobres filhos por umas lambisgóias de touca branca, numa algaravia teuto-italo-nipônica que o diabo entenda. Vieram estas corujas civilizar-nos; mas que saudades da tia velha que em vez. de 
civilização requentada a $70 \$ 000$ réis por mês, afora bicos, nos apavorava de graça.

$(\mathrm{s} / \mathrm{n})$

Com capa assinada por J. Wash Rodrigues, O sacy Pererê pode ser lido na clave do primitivismo que, mais tarde, gera tanto o Macunaima de Mário de Andrade quanto, no além - mar europeu, as máscaras africanas de Picasso. Descosidos, os depoimentos são colcha de retalhos na qual se alinhavam frouxamente opiniões relativas ao mundo sobrenatural, dissertações sobre o folclore brasileiro e manifestações menos ou mais veladas de menosprezo pela cultura popular. No mesmo diapasão, as pinturas e esculturas reproduzidas alternam representações realistas (?!) do saci com outras que rompem com o traço figurativo. ${ }^{15}$

Ultrapassadas a capa do livro, a introdução e a dedicatória, o leitor chega aos depoimentos. A transcrição de alguns fragmentos deles ilustra a variedade de registros.

Manuel Barroca - de quem diz o organizador do livro que pelos modos e apesar de assinar-se Mané é homem da cidade, escovadíssimo e que voluntariamente depõe em tom dialetal como quem o conbece a fundo - realmente escreve de forma bastante original para a época:

\footnotetext{
Aqui das nossas banda exeste muito desse sogeitinho; é verdade, elle exeste e aparece as veis pr' a gente; u mêmo quando éra mais menó, vi de ua feita um tinhosinho desse; eu tava carpinando um feijaosinho que nois prantemo, na berada de ua estrada veia que descanba pra casa de um tar joaquim Porquero; quando se não quando, eu escuitei um baruinho semiante um arrastadinho de saia de muié ansin na beradinha do caminho, garrei a oiá firme pra o tar baruinho; se formô-se na coisa que nois chama rodamoinho, bem no meio da estrada, alevantava as foia de mato pra o ar. (p. 35)
}

Já no depoimento de M.L. de Oliveira Filho, o informalismo é mais próximo da modalidade padrão, mas ainda assim cheio de marcas 
de oralidade e salpicado de aspas que sugerem a consciência do autor de momentos de desvio maior da norma:

[...] Já com o fôlego curto "trupiquei" e m'estendi; o ronco passou por riba me deixando mais frio do que "largato": cruiz credo, Nossa Senhora! gritei tres vezes, deitado de boca p'ro chão.

"Garrei" no sono. Acordei com duas braças de sol, que nem pinto de suado. Estava rentinho coma tapera do Supriano, sem chapéu, vendendo farinha; tinha perdido a cinta com a faca e o "arreadô" prateado. (pp. 65-66)

Em outros depoimentos recolhidos no livro, o registro lingüístico é menos marcado:

Segundo me contou uma preta velha e leal amiga de todos os meus, o Sacy, um negrinho retinto de um metro de altura, porém velho, de uma perna só...

Em minha meninice, parte passada na faženda de meu avô paterno, $e$ parte numa pequena cidade do estado do Rio, o Sacy exercia uma influência extraordinária não só no espírito da criançada, como também no de muito negro velho e no de muito caboclo crédulo (p. 119)

Conversando ontem em casa de um meu amigo, sobre a questão do sacy pererê, que tanto interesse tem provocado e como eu the contasse alguns fatos ouvidos na minha infância, e que me ficaram gravados na memória, interpelou-me ele porque não concorria com o pouco que sabia para a elucidação do caso da mitologia brasileira lembrado pelo SR M.L. É, portanto, para satisfazer o desejo de men ilustre amigo que venho à sua presença. (p. 197)

À galeria não falta nem mesmo o depoimento do próprio saci, provavelmente da autoria de Monteiro Lobato. Muito engraçado, o texto fortalece a tese de que o livro que Lobato organiza tem um eixo diretor: a defesa da cultura rural brasileira, agora pela boca do saci reclama da imagem que lhe traçam certas passagens do livro: 
Bom dia. Aqui, nos arredores da Paulicéa, onde ando "paráparando" desde que fui expulso da cidade pelas histórias da carochinha e dos anões cervejeiros da nebulosa Germânia, soube que o "Estadinho" "bavera" publicado meu retrato e ia fazer minha biografia.

Quis ver o engrossamento. Passei a mão nuns vintens chãnchãns que vinha juntando no buraco de um pau podre desde o tempo que D. Pedro virou onça no Ipiranga e comprei a sua folha.

Gostei um pouco do que ela diria no primeiro número, mas inquisilei com 0 retrato. $[\ldots]$ (p. 117)

Como se vê, o registro dos depoimentos oscila entre o descuido intencional (e provocativo) no uso da norma padrão e diferentes graus de respeito a ela. Já no plano dos efeitos de sentido, faz-se presente, na maioria dos depoimentos, o distanciamento entre quem relata e a matéria relatada: é como se o saci só chegasse à vida dos leitores de $O$ Estado de $S$. Paulo mediado por pretas velhas, pelo mundo rural, pela boca de caboclos ditos crédulos.

Em conseqüência, as informações que Monteiro Lobato recebe colocam seus informantes a cavaleiro daquilo que relatam, construindo para si patamar de superioridade que lhes permite rirem-se da credulidade alheia ou, então - também de forma superior e esclarecida - elucidarem a controvérsia.

Nesta leitura, O sacy parece inaugurar os diferentes formatos pelos quais a cultura popular brasileira vai fazer-se presente na arte culta. De Juca Mulato (Menotti del Picchia, 1917) a Macunaima (Mário de Andrade, 1928) e a Cobra Norato (Raul Bopp, 1931), dos contos de Lobato (Urupês, 1918; Cidades mortas 1919; Negrinha, 1920) a Waldomiro Silveira (Os caboclos, 1920; Nas serras e nas furnas, 1931; Mixuangos, 1937; Leréias, 1945), o enfoque é parecido, para ficarmos apenas na literatura que freqüenta histórias literárias, com exceção dos marginais paulistas Lobato \& Waldomiro. 
Nesse resgate do imaginário popular, O Sacy Pererê tem uma face olhando para o Brasil rural e outra para o Brasil urbano. Se o Brasil rural comparece no toque de sinceridade de muitos dos depoimentos, o Brasil do asfalto manifesta-se já no próprio projeto, uma vez que por hipótese a rede de leitores - e, mais ainda, de leitores que se transformam em colaboradores de jornal - é citadina, o que talvez seja responsável pelos traços de ironia e desfastio com que vários depoimentos relacionam a figura do sacy a atraso, negros, caboclos e vida rural.

\section{Monteiro Lobato e a modernidade perneta}

No interior desse curioso livro, para o qual colaboram tantas e tão variadas vozes, Lobato abre espaço para patrocinio comercial da obra, que se inicia e se encerra com anúncios ilustrados de página inteira que vendem diferentes produtos.

$\mathrm{Na}$ abertura, quatro anúncios vendem, respectivamente: a) máquinas de escrever Remington; b)chocolates Lacta; c) cigarros castelões e d) artigos fotográficos. No fechamento, mais três textos publicitários recomendam e) louças e objetos de arte, f) o chocolate Falchi e g) a drogaria e perfumaria Bráulio \& Cia. (cf. as imagens ao final deste artigo)

Com tal procedimento, o livro traz para suas páginas a mesma mistura de informação e publicidade e a mesma mixórdia de estilos e gêneros que caracterizam as páginas de um jornal, o que combina bem com uma obra, como já se disse, talvez não por acaso editada e impressa nas oficinas de um jornal.

Embora na dedicatória das epopéias a tradição clássica reserve o espaço para os rapapés aos Mecenas (que ao tempo de leitura restrita à elite aristocrática viabilizavam a produção de livros), ainda hoje é inusitado (e o era muito mais nas vésperas dos anos 20 do século passado) uma explicitação tão clara da dimensão comercial de livros e de leitura. 
O procedimento torna-se ainda mais saboroso e sugestivo, uma vez que os anúncios nele incluídos recorrem à própria figura do saci como agente de vendas. É o negrinho perneta, de cachimbo e capuz que vende o que vendem os anúncios. Enquanto agente de vendas, o saci vende sua mercadoria através de gestos bastante semelhantes àqueles que, marcados pela violência, travessura e irreverência, são relatados em diferentes testemunhos do livro. É como se o saci saltasse das páginas de opinião dos leitores para a página de classificados.

Dentre as mercadorias vendidas pelo saci, algumas - como máquina de escrever e material fotográfico - impõem-se como signos da modernidade, o que se intensifica ainda mais pela utilização, no texto publicitário, de linguagens modernas, como o balão das histórias em quadrinhos (na venda dos artigos fotográficos) ou a sintaxe que integra o verbal e o visual no anúncio da Remington.

Se aceitamos a tese de que a contradição é a marca maior de Lobato, ${ }^{16}$ começaremos a ver $O$ sacy como obra essencialmente lobatiana, principalmente se atentarmos que a contradição já nasce no próprio projeto do qual resultou o livro.

O projeto, ao mesmo tempo em que resgata a figura tradicional e provinciana do saci (conotação que se mantém mais tarde no uso que Lobato faz desta figura, por exemplo no conto "Pedro Pichorra") visa transformar o negrinho perneta em instância da resistência à europeização cultural representada pelos anõezinhos que enfei(t)avam a pacata praça paulistana.

Nos anúncios, no interior do mesmo livro em que representa penhor de resistência cultural, o saci de Lobato contracena com a mais gritante modernidade, que é tão estrangeira como os anõezinhos com os quais Lobato embirra.

O que faz o livro O Sacy Pererê protagonizar uma contradição, de envergadura muito maior.

A figura do saci, em tantos depoimentos estigmatizada pelo provincianismo que a marca, mas ainda assim proposta como alternativa 
brasileira à mitologia européia, quando vende a máquina de escrever e o material fotográfico vende uma tecnologia que, além de emblema de modernidade, representa uma modernidade tão importada e tão estrangeira quanto os pobres anõezinhos de jardim que deram origem a toda a história, acusados de serem anõezinhos fora do lugar...

Fora de lugar?

Eles e todos os Monteiros e todos os Lobatos!

É por ser assim tantos, que Monteiro Lobato ainda tem o que dizer ao Brasil de hoje, e prossegue gerando polêmicas tão acesas quanto aquelas que pontilharam sua vida, toda ela marcada pela perplexidade face aos diferentes brasis que coexistiam e continuam coexistindo entre o Oiapoque e o Chuí.

Brasis muito bem representados na pluralidade de vozes, de linguagens e de pontos de vista dessa obra de estréia de Monteiro Lobato que dialoga de igual para igual com os seus posteriores contos e histórias, infantis e não infantis.

\section{Notas}

1 Versão anterior deste texto foi apresentada como palestra de encerramento do seminário Leitura e desenvolvimento social, organizado pela PUCRS, pela UFRGS e pelo Instituto Marc Chagall em Porto Alegre, em 02/07/1998, e foi posteriormente publicada em O escritor (Jornal da União Brasileira dos Escritores), no 85, julho 1998, pp. 07-08.

2 Cf. Lajolo, M. e Zilberman, R. O preço da leitura. São Paulo: Ática, 2001.

3 Cf. Darnton, Robert. L'aventure de l'Éncyclopedie (1775-1800). Librairie Académique Perrin, 1982.

4 Monteiro Lobato. Cartas escolhidas. 1º tomo. São Paulo: Brasiliense, 1964, p. 187.

5 Monteiro Lobato: A barca de Gleyre. 2o tomo. São Paulo: Brasiliense, 1957, p. 231.

6 Cf. Lajolo, M. "Um Dom Quixote no caminho da leitura”. In Do mundo da leitura para a_leitura do mundo. $\sigma^{\text {a }}$ ed. São Paulo: Ática. 2000, pp. 94-103. Cf. também Adriana Silene Vieira. Um inglês no sítio do Picapan Amarelo (Um estudo de Peter Pan). Dissertação de Mestrado, mimeo, IEL, financiamento CAPES. Cf. ainda Cilza C. Bignotto. Duas leituras da 
infância segundo Monteiro Lobato. Dissertação de Mestrado. IEL. Financiamento Fapesp. Ambas as teses estão disponíveis em http:// www.unicamp.br/iel/ memoria.

7 Sachetta (cf. Bibliografia, p. 200) registra que em 1925, "Sob encomenda do laboratório Fontoura, Monteiro Lobato adapta Jeca Tatuzinho para promoção de seus produtos, em especial do Biotônico". A agilidade de Monteiro Lobato para parcerias manifesta-se também na informação de Edgar Cavalheiro (cf. Bibliografia, vol. II, p. 724) de que Lobato também redigiu anúncios para a máquina de escrever Royal, para Salsaparrilha, para a casa lotérica que possuía, além de historietas para o Café Jardim.

8 Essa informação vem de pesquisa em curso para doutorado e financiada pela Fapesp desenvolvida por Milena Martins, que estuda o que, com muita propriedade, chama de "O mundo dos livros" na Revista do Brasil, que, entre 1918 e 1925, teve grande influência de Monteiro Lobato, primeiro seu editor e depois seu proprietário.

9 Monteiro Lobato. A barca de Gleyre. 2 tomo. São Paulo: Brasiliense, 1957, pp. 373375.

10 Monteiro Lobato. O Sacy Pererê: resultado de um inquérito. Ed. Fac-similar. Fundação Odebrecht/Fundação Banco do Brasil.

11 Juó Bananere é o pseudônimo de Alexandre Marcondes Machado (1892-1933), que em 1915 publica La divina Increnca.

12 O sacy e as pretas, aquarela de Richter; Sacy na estrada, por Fantomas; Sacy laçados, estatueta de M. Vellez; Sacy satisfeito (sem autor); medalhão em gesso de R. Cipicchia; Sacy na Cavalhada, óleo de R. Cipicchia; O sacy e o caipira, aquarela de Richter; Sacy destelhando casa, aquarela de Norfini; Sacy assustando preto, aquarela de Norfini; Sacy no rodamoinho, aquarela de Norfini; Sacy na cavalhada, aquarela de Norfini; Sacy Pererê, escultura de João Frick; Sacy no rodamoinho, aquarela de $\mathrm{H}$. della Latta,

13 Sacy Pererê. Polka dedicada ao Estadinho de Nogueira de Lima.

14 Cf. Marisa Lajolo. "Negros e negras em Monteiro Lobato". Apud Lendo e escrevendo Monteiro Lobato. Belo Horizonte: Autêntica, 1999, pp. 65-82.

15 A inclusão de reprodução de quadros e estatuetas nesse livro, alguns de inspiração antiacadêmica, dá uma nota curiosa às antológicas críticas de Monteiro Lobato à exposição de pintura de Anita Malfatti (1917). Relativamente ao assunto, cf. Tadeu Chiarelli. Um Jeca nos vernissagens paulistas. São Paulo: Edusp, 1995. 
16 Lajolo, M. Monteiro Lobato: um brasileiro sob medida. São Paulo: Moderna, 2000.

\section{Bibliografia}

Azevedo, Carmen; Camargos, Márcia; Sachetta, Vladimir: Monteiro Lobato: furacão na Botucúndia. São Paulo: Senac, 1997.

Bignotto, Cilza C. Duas leituras da infância segundo Monteiro Lobato. Dissertação de Mestrado. IEL, Fapesp. http:/ / www.unicamp.br/iel/ memoria.

Chiarelli, Tadeu. Um jeca nos vernissagens paulistas. São Paulo: Edusp, 1995.

Darnton, Robert. L'aventure de l Éncyclopedie_(1775-1800). Librairie Académique Perrin, 1982.

Cavalheiro, Edgard. Monteiro Lobato: vida e obra. São Paulo: Brasiliense, 1956.

Lajolo, M e Zilberman, R. O preşo da leitura. São Pauo: Ática, 2001.

Lajolo, M. "Negros e negras em Monteiro Lobato". Apud Lendo e escrevendo Monteiro Lobato. Belo Horizote: Autêntica, 1999, pp. 65-82.

Lajolo, M. Um Dom Quixote no caminho da leitura. In Do mundo da leitura para a leitura do mundo. São Paulo: Ática, 2000.

Lajolo, M. Monteiro Lobato: um brasileiro sob medida. São Paulo: Moderna, 2000.

Monteiro Lobato. A barca de Gleyre. $2^{\circ}$ tomo. São Paulo: Brasiliense, 1957.

Monteiro Lobato. Cartas escolbidas. 1º tomo. São Paulo: Brasiliense, 1964.

Monteiro Lobato. O Sacy Pererê: resultado de um inquérito. Ed. fac-similar. Fundação Odebrecht/Fundação Banco do Brasil.

Vieira, Adriana Silene. Um inglês no sítio do Picapau Amarelo (Um estudo de Peter Pan). Dissertação de Mestrado, mimeo, IEL, CAPES. http:// www.unicamp.br/iel/memoria. 


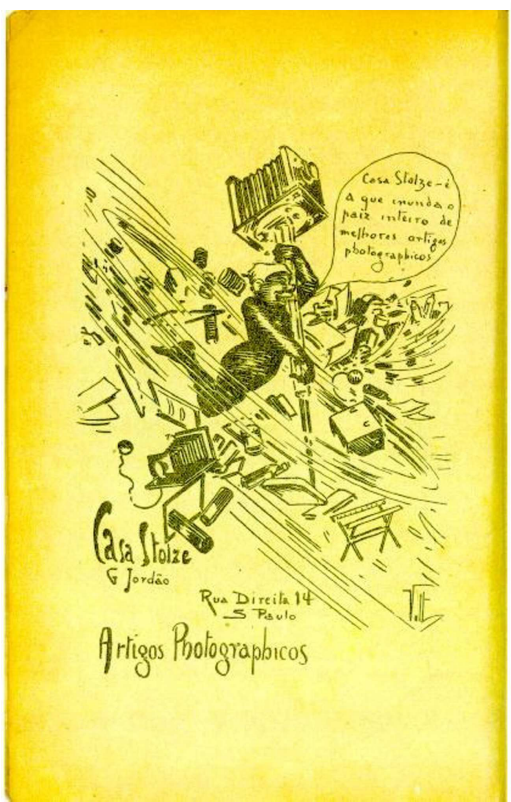

Fig. 01

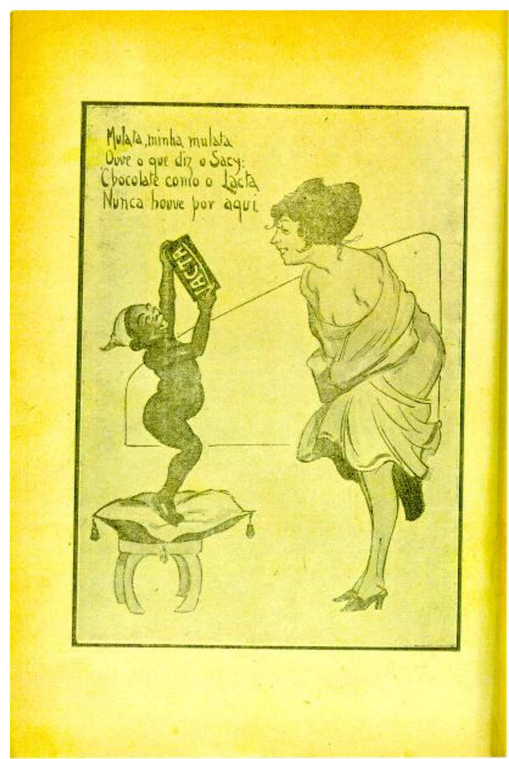

Fig. 03

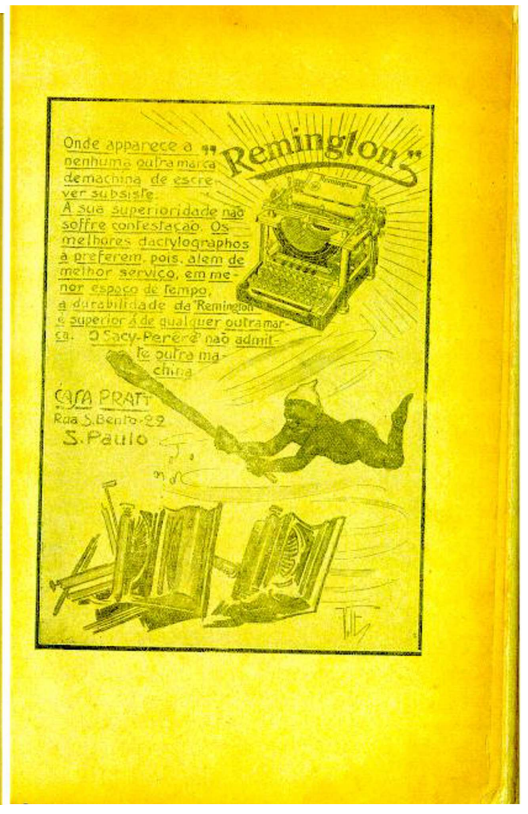

Fig. 02

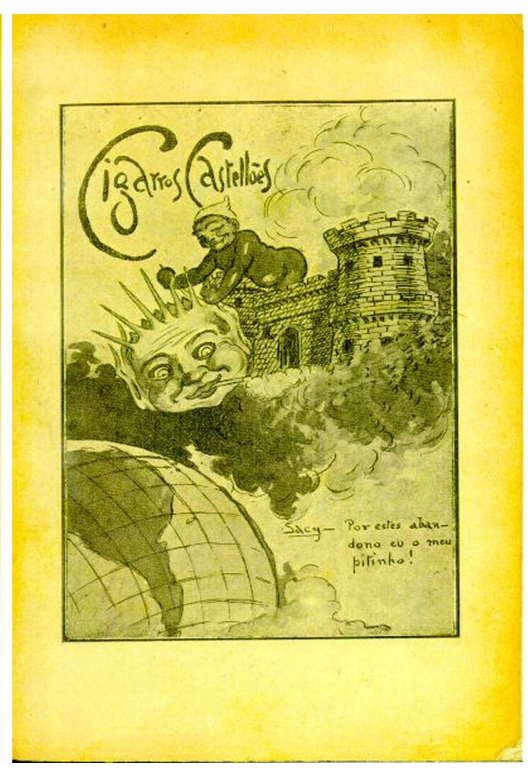

Fig. 04 


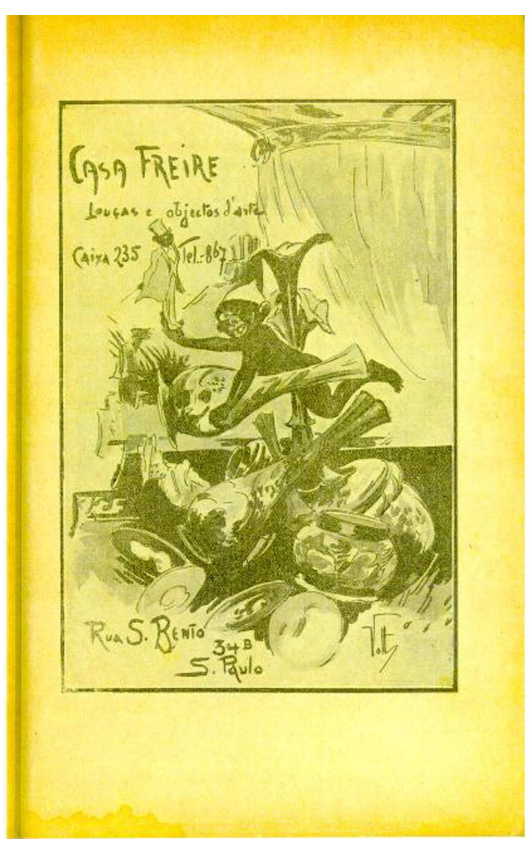

Fig. 05 